\title{
Interstitial 1q21.1 Microdeletion Is Associated with Severe Skeletal Anomalies, Dysmorphic Face and Moderate Intellectual Disability
}

\author{
Bruno F. Gamba ${ }^{a}$ Roseli M. Zechi-Ceide ${ }^{a}$ Nancy M. Kokitsu-Nakata ${ }^{a}$ \\ Siulan Vendramini-Pittoli ${ }^{a} \quad$ Carla Rosenberg $^{\text {b }}$ Ana C.V. Krepischi Santos ${ }^{b}$ \\ Lucilene Ribeiro-Bicudo $^{c}$ Antonio Richieri-Costa ${ }^{a}$ \\ aDepartment of Clinical Genetics, Hospital for Rehabilitation of Craniofacial Anomalies (HRCA), University of São \\ Paulo, Bauru, ${ }^{b}$ Centro de Estudos do Genoma Humano, University of São Paulo, São Paulo, and ' Departamento de \\ Genética, Instituto de Ciências Biológicas, Universidade Federal De Goias, Goiania, Brazil
}

\section{Established Facts}

- Deletions reported in the 1q21.1 region are clinically heterogeneous, ranging from subtle phenotypic manifestations to severe congenital heart defects and/or neurodevelopmental findings.

\section{Novel Insights}

- Deletions of some genes related to the process of bone modeling in our patient - ITGA10 and PIAS3 - could be contributing to the phenotypic skeletal findings observed.

\section{Key Words}

Dysmorphic features $\cdot$ Intellectual disability $\cdot$ Microdeletion 1q21.1 Skeletal anomalies

\section{Abstract \\ We report on a Brazilian patient with a 1.7-Mb interstitial mi- crodeletion in chromosome 1q21.1. The phenotypic charac- teristics include microcephaly, a peculiar facial gestalt, cleft lip/palate, and multiple skeletal anomalies represented by malformed phalanges, scoliosis, abnormal modeling of ver- tebral bodies, hip dislocation, abnormal acetabula, feet anomalies, and delayed neuropsychological development. Deletions reported in this region are clinically heteroge-}

neous, ranging from subtle phenotypic manifestations to severe congenital heart defects and/or neurodevelopmental findings. A few genes within the deleted region are associated with congenital anomalies, mainly the $R B M 8 A$, DUF1220, and HYDIN2 paralogs. Our patient presents with a spectrum of unusual malformations of 1q21.1 deletion syndrome not reported up to date.

(c) 2016 S. Karger AG, Basel

Deletions involving the 1q21.1 region are mainly associated with neurodevelopmental disorders [BaselVanagaite et al., 2011], congenital heart disease [Digilio et al., 2013], variable dysmorphic features, as well as

\section{KARGER}

E-Mail karger@karger.com www.karger.com/msy
(C) 2016 S. Karger AG, Basel

1661-8769/16/0076-0344\$39.50/0
Antonio Richieri-Costa, MD

HRAC, University of São Paulo PO Box 620

Bauru, SP 17012-900 (Brazil)

E-Mail richieri@usp.br 

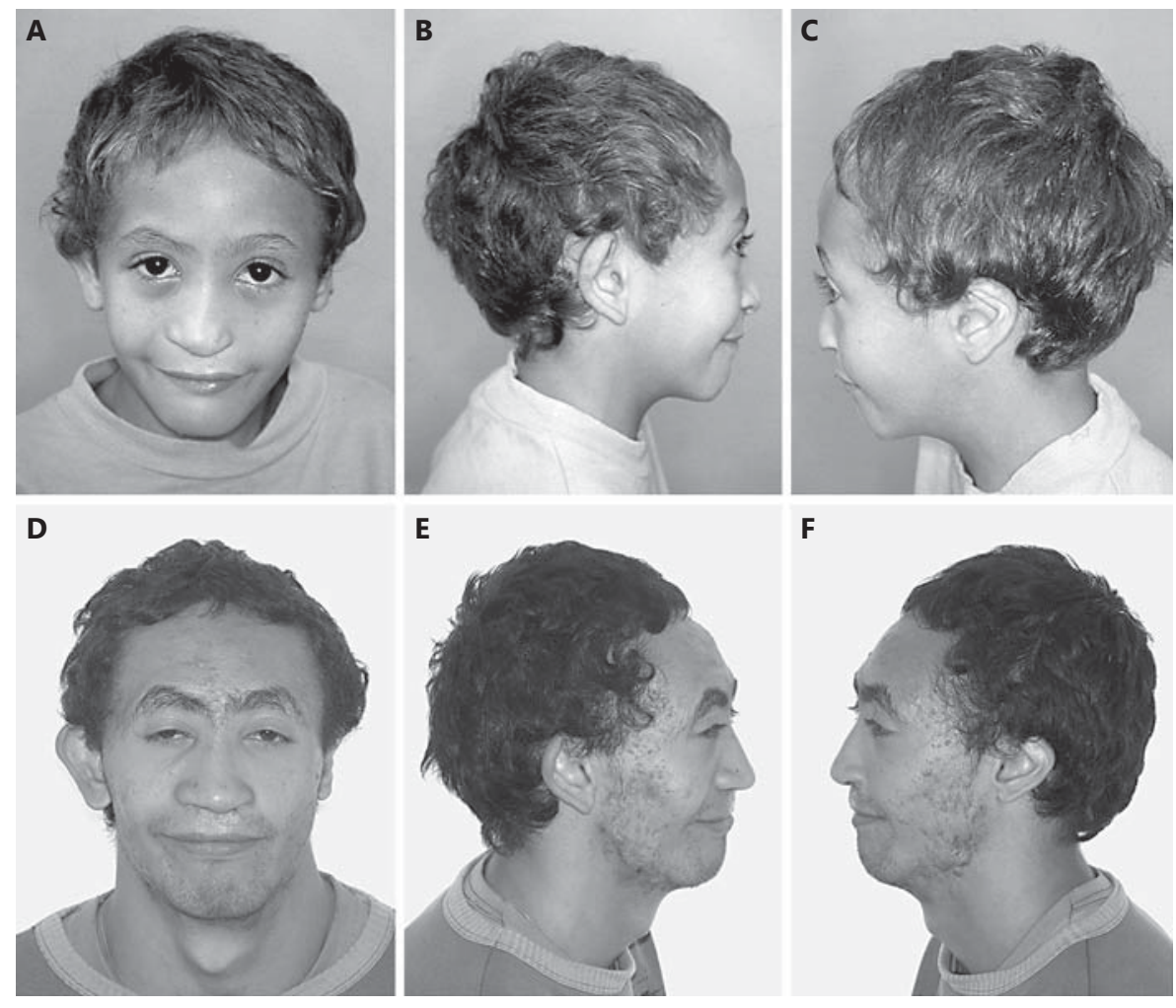

Fig. 1. A-F The patient at age $9(\mathbf{A}-\mathbf{C})$ and 19 years (D-F). A small skull, sloping forehead, synophrys, arched eyebrows, a flat nose, prominent ears, large conchae, hypoplastic tragus and lobules, left cleft lip/palate, and a large mouth are shown.

congenital anomalies [Brunetti-Pierri et al., 2008; Velinov and Dolzhanskaya, 2010], and with thrombocytopenia-absent radius syndrome (OMIM 274000) due to a deletion in the RBM8A gene [Papoulidis et al., 2014]. Phenotypically normal carriers have also been reported [Mefford et al., 2008]. In this study, the patient presents with several clinical findings rarely observed in patients with a 1q21.1 deletion, which include cleft lip/palate, dental anomalies (involving size, shape, and form), hearing loss, and skeletal involvement not related to thrombocytopenia-absent radius syndrome. These findings could be attributed to the effect of other genes encompassed in this deletion and manifesting as a contiguous gene syndrome.

\section{Patient and Methods}

\section{Case Report}

The male patient (fig. $1 \mathrm{~A}-\mathrm{F}$ ) is the sixth child of a 28 -year-old woman G7P6A1 and her 29-year-old nonconsanguineous husband. Minor anomalies were not detectable in the parents. The pregnancy was uncomplicated with no history of exposure to teratogens. The mother had a history of threatened miscarriage at 4 months of pregnancy. Delivery was normal at term and birthweight was 2,450 $\mathrm{g}$ (<3rd percentile); length was not recorded. A cleft lip/ palate was detected. Clinical examination at age 19 months showed: weight 7,600 $\mathrm{g}(<3 \mathrm{rd}$ percentile), length $71 \mathrm{~cm}$ ( $<3 \mathrm{rd}$ percentile), and $\mathrm{OFC} 43 \mathrm{~cm}$ ( $>2$ nd percentile). A reevaluation at the age of 22 years and 8 months revealed: weight $25 \mathrm{~kg}$ ( $<3 \mathrm{rd}$ percentile), length $130.5 \mathrm{~cm}$ (<3rd percentile), and OFC $48 \mathrm{~cm}$ (<3rd percentile). He presented with microcephaly, a sloping forehead, synophrys, arched eyebrows, a flat nose, prominent ears, large conchae, hypoplastic tragus and lobules, left cleft lip/palate, a large mouth, hypodontia, large left central maxillary incisor, aberrant crown morphology, short hands, mild camptodactyly (mainly of 5th finger), bilateral hypoplasia of the distal phalanges of fingers 2 and 3, with agenesis/hypoplasia of the nails (fig. 2A, B), halluces valgi, a wide gap between toes 1 and 2, proximal syndactyly between toes 2 and 3 , a short 5 th toe (fig. 3A, B), and bilateral hip dislocation. Neuropsychological development and language acquisition were delayed. $\mathrm{X}$-rays of the hands (fig. 2C, D) showed gross and misshapen proximal phalanges of fingers 2-3, radial clinodactyly of finger 2, hypoplastic distal phalanges of fingers 2-3, abnormal 'bird-like beak' modeling of the right distal phalanx of finger 2 , and a small bony fragment distal to the phalanx of finger 3 as well as a dislocation of the metacarpal phalangeal joint of both thumbs. In both feet, the median and distal phalanges of toes 3-5 are hypoplastic with halluces valgi (fig. 3C). X-rays of the vertebral column revealed a narrow intervertebral disc space at T10-L5, thoracolumbar scoliosis, and sacral hemivertebra. MRI showed a left choanal atresia; the central nervous system was normal. Audiological evaluation performed at the age of 21 years revealed a bilateral mixed hearing loss. The results of routine laboratory blood tests were normal. 
Fig. 2. A-D The hands of the patient showing mild camptodactyly (mainly of 5th finger), short hands, bilateral hypoplasia of the distal phalanges of fingers 2 and 3 , with agenesis/hypoplasia of the nails (A, B). Xrays of the hands show gross and misshapen proximal phalanges of fingers 2 and 3, radial clinodactyly of finger 2 , hypoplastic distal phalanges of fingers 2 and 3, abnormal 'bird-like beak' modeling of the right distal phalanx of finger 2 as well as a small bony fragment distal to the phalanx of finger 3 , and a dislocation of the metacarpal phalangeal joints of both thumbs (C, D).
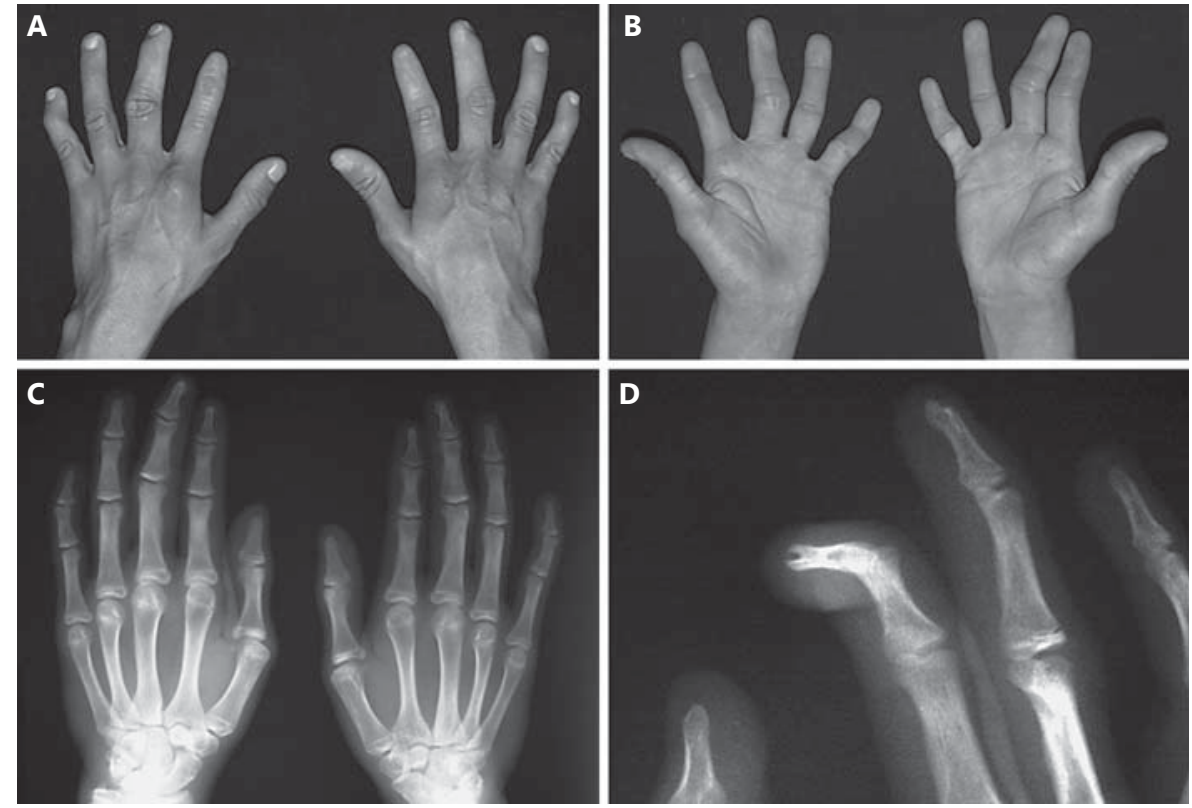
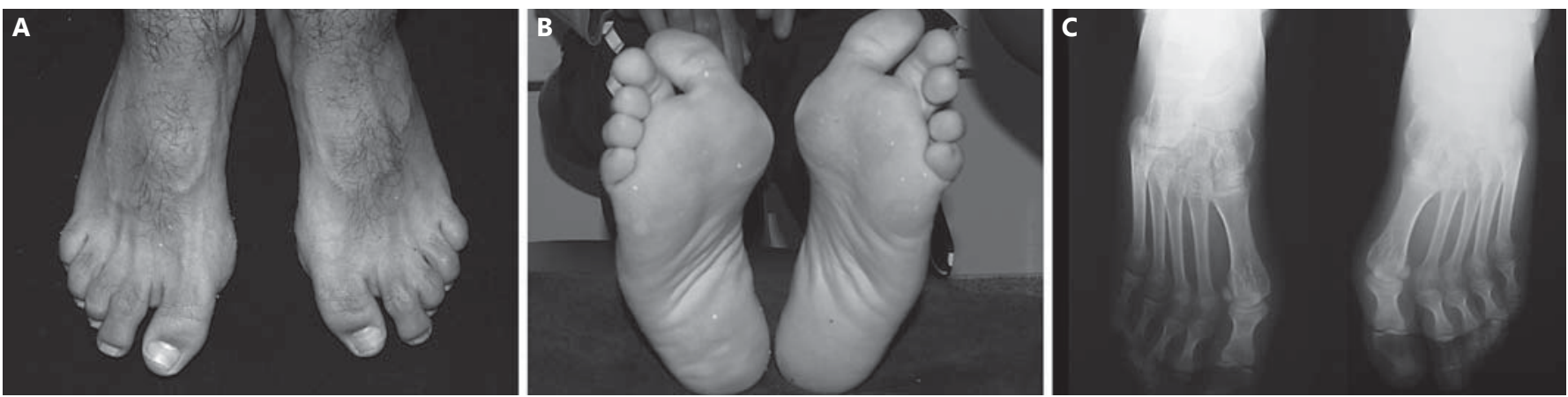

Fig. 3. A-C The feet of the patient showing a wide gap between toes 1 and 2, proximal syndactyly between toes 2 and 3, a short 5th toe $(\mathbf{A}, \mathbf{B})$, and marked hypoplasia of median and distal phalanges of toes 3 and 5 with bilateral halluces valgi (C).

\section{Cytogenetic and Molecular Analysis}

Cytogenetic analysis of peripheral blood lymphocytes from the patient, performed using standard techniques and processed by G-banding (550 bands), was normal. Screening for mutations in SHH, TGIF, SIX3, PTCH1, GLI2, GAS1, and ZIC2 genes was unremarkable. Array-CGH using the Human Genome CGH Microarray $60 \mathrm{~K}$ detected an interstitial deletion in band 1q21.1 of 1.7 $\mathrm{Mb}$, spanning from position 144.610 .516 to $146.354 .478 \mathrm{bp}$ (UCSC Genomic Bioinformatics, GRCh37/hg19, http://genome. ucsc.edu) and encompassing 44 RefSeq annotated genes (22 protein coding genes, 6 tRNA coding genes, 1 snRNA coding gene, 6 hypothetical genes, and 9 pseudogenes; http://www.ncbi.nlm.nih. gov/mapview). Parental DNA was not available for molecular testing.

\section{Results and Discussion}

The 1q21.1 deletions have been associated with a heterogeneous clinical phenotype mainly presenting with intellectual disabilities, seizures, psychosis, language disorder, autism, and microcephaly [Brunetti-Pierri et al., 2008; Stefansson et al., 2008; Basel-Vanagaite et al., 2011; Natera-De Benito et al., 2015; Bernier et al., 2016]. Congenital heart defects and a wide range of minor congenital anomalies such as frontal bossing, deep-set eyes, camptodactyly, postaxial polydactyly, mild interdigital membranes, clavicular pseudoarthrosis, rib anomalies, and syndactyly of toes 2 and 3 have been observed in these 
patients, however, without characterizing a distinct facial gestalt [Christiansen et al., 2004; Brunetti-Pierri et al., 2008; Mefford et al., 2008; Velinov and Dolzhanskaya, 2010; Houeijeh et al., 2011; Rosenfeld et al., 2012; Digilio et al., 2013]. Asymptomatic carriers are found in family studies with this microdeletion [Brunetti-Pierri et al., 2008; Mefford et al., 2008; Bottillo et al., 2013; Bernier et al., 2016]. According to DECIPHER (http://decipher. sanger.ac.uk), microdeletions encompassing the region 1q21.1 (144,610,516-146,354,478 bp) are associated with different phenotypic combinations of the listed disorders, reinforcing the causal relationship of this microdeletion with the phenotype of our patient. However, the additional findings represent a unique cluster of congenital malformations mainly characterized by a unilateral cleft lip/palate, abnormal teeth, atypical digital anomalies, abnormal hands, and a peculiar facial gestalt.

Clinical and molecular studies have associated microcephaly with the hemizygous state of 2 main genes: HYDIN and RBM8A [Brunetti-Pierri et al., 2008; Haldeman-Englert and Jewett, 2015]. Evidence from mouse studies showed that homozygous inactivating mutations of the Hydin gene result in hydrocephalus mice due to impairment of the ciliated ependymal cell lining of the lateral third and fourth ventricles [Davy and Robinson, 2003]. Therefore, the observation of the HYDIN paralog expressed in humans may be a candidate gene for microcephaly, since it is only expressed in the brain and is important in head size determination [Brunetti-Pierri et al., 2008; Olbrich et al., 2012]. Recently, it was shown that the $R B M 8 A$ gene within the 1q21.1 region, besides its role in the thrombocytopenia-absent radius syndrome genesis, also disrupts the embryonic cortical development resulting in neurodevelopmental phenotypes associated to microcephaly [Mao et al., 2015; Zou et al., 2015].
Some of the signs seen in our patient are related to the involvement of skeletal structures both in differentiation as well as in modeling, which is clearly observed in the abnormal modeling and misshaping of the phalangeal complement. The axial skeleton represented by the vertebral column and ribs was also involved, and the main malformations observed were abnormally modeled vertebral bones, hemivertebra, and spina bifida. Recently, it was shown that mutations in the ITGA10 gene in the Norwegian Elkhound and Karelian Bear Dog breeds result in a recessive autosomal chondrodysplasia; however, up to date, no evidence of involvement of this gene in human disease was demonstrated [Kyöstilä et al., 2013]. It is possible that ITGA10 and PIAS3, both related to the process of bone remodeling [Liu et al., 2014; Napimoga et al., 2015 ] and deleted in our patient, could be contributing to the phenotypic variability observed, next to other unidentified genetic or environmental factors that remain essential for the expression of the clinical signs in each individual [Rosenfeld et al., 2012].

\section{Statement of Ethics}

The authors have no ethical conflicts to disclose.

\section{Disclosure Statement}

The authors have no conflicts of interest to declare.

\section{References}

Basel-Vanagaite L, Goldberg-Stern H, MimouniBloch A, Shkalim V, Böhm D, Kohlhase J: An emerging 1q21.1 deletion-associated neurodevelopmental phenotype. J Child Neurol 26: 113-116 (2011).

-Bernier R, Steinman KJ, Reilly B, Wallace AS, Sherr EH, et al: Clinical phenotype of the recurrent 1q21.1 copy-number variant. Genet Med 18:341-349 (2016).
Bottillo I, Castori M, De Bernardo C, Fabbri R, Grammatico B, et al: Prenatal diagnosis and post-mortem examination in a fetus with thrombocytopenia-absent radius (TAR) syndrome due to compound heterozygosity for a 1q21.1 microdeletion and a RBM8A hypomorphic allele: a case report. BMC Res Notes 6:376 (2013).

Brunetti-Pierri N, Berg JS, Scaglia F, Belmont J, Bacino CA, et al: Recurrent reciprocal 1q21.1 deletions and duplications associated with microcephaly or macrocephaly and developmental and behavioral abnormalities. Nat Genet 40:1466-1471 (2008).
Christiansen J, Dyck JD, Elyas BG, Lilley M, Bamforth JS, et al: Chromosome 1q21.1 contiguous gene deletion is associated with congenital heart disease. Circ Res 94:1429-1435 (2004).

Davy BE, Robinson ML: Congenital hydrocephalus in hy3 mice is caused by a frameshift mutation in Hydin, a large novel gene. Hum Mol Genet 12:1163-1170 (2003).

Digilio MC, Bernardini L, Consoli F, Lepri FR, Giuffrida MG, et al: Congenital heart defects in recurrent reciprocal 1q21.1 deletion and duplication syndromes: rare association with pulmonary valve stenosis. Eur J Med Genet 56:144-149 (2013).
Severe Skeletal Anomalies in Interstitial 1q21.1 Microdeletion 
Haldeman-Englert CR, Jewett T: 1q21.1 Recurrent microdeletion, in Pagon RA, Adam MP, Ardinger $\mathrm{HH}$, Wallace SE, Amemiya A, et al (eds): GeneReviews ${ }^{\circledR}$ [Internet] (University of Washington, Seattle 1993-2016). Initial posting: 2011 Feb 24; last update: $2015 \mathrm{Nov}$ 12).

Houeijeh A, Andrieux J, Saugier-Veber P, David A, Goldenberg A, et al: Thrombocytopeniaabsent radius (TAR) syndrome: a clinical genetic series of 14 further cases. Impact of the associated 1q21.1 deletion on the genetic counselling. Eur J Med Genet 54:e471-477 (2011).

Kyöstilä K, Lappalainen AK, Lohi H: Canine chondrodysplasia caused by a truncating mutation in collagen-binding integrin alpha subunit 10. PLoS One 8:e75621 (2013).

Liu T, Qin AP, Liao B, Shao HG, Guo LJ, et al: A novel microRNA regulates osteoclast differentiation via targeting protein inhibitor of activated STAT3 (PIAS3). Bone 67:156-165 (2014).
Mao H, Pilaz LJ, McMahon JJ, Golzio C, Wu D, et al: Rbm8a haploinsufficiency disrupts embryonic cortical development resulting in microcephaly. J Neurosci 35:7003-7018 (2015).

- Mefford HC, Sharp AJ, Baker C, Itsara A, Jiang Z, et al: Recurrent rearrangements of chromosome 1q21.1 and variable pediatric phenotypes. N Engl J Med 359:1685-1699 (2008).

Napimoga MH, Demasi AP, Jarry CR, Ortega MC, de Araújo VC, Martinez EF: In vitro evaluation of the biological effect of SOFAT on osteoblasts. Int Immunopharmacol 26: 378-383 (2015).

Natera-De Benito D, Vidal-Esteban A, SanchezDel Pozo J, Moreno-Garcia M, Suela-Rubio J, et al: Phenotypic variability of the 1q21.1.microdeletion syndrome in members of the same family: relevance of detection of neuropsychiatric disorders for diagnosis of genetic syndromes (in Spanish). Rev Neurol 61:550-556 (2015).

Olbrich H, Schmidts M, Werner C, Onoufriadis A, Loges NT, et al: Recessive HYDIN mutations cause primary ciliary dyskinesia without randomization of left-right body asymmetry. Am J Hum Genet 91:672-684 (2012).
Papoulidis I, Oikonomidou E, Orru S, Siomou E, Kontodiou M, et al: Prenatal detection of TAR syndrome in a fetus with compound inheritance of an RBM8A SNP and a 334-kb deletion: a case report. Mol Med Rep 9:163-165 (2014).

Rosenfeld JA, Traylor RN, Schaefer GB, McPherson EW, Ballif BC, et al: Proximal microdeletions and microduplications of 1q21.1 contribute to variable abnormal phenotypes. Eur J Hum Genet 20:754-761 (2012).

Stefansson H, Rujescu D, Cichon S, Pietiläinen $\mathrm{OP}$, Ingason $\mathrm{A}$, et al: Large recurrent microdeletions associated with schizophrenia. Nature 455:232-236 (2008).

-Velinov M, Dolzhanskaya N: Clavicular pseudoarthrosis, anomalous coronary artery and extra crease of the fifth finger-previously unreported features in individuals with class II 1q21.1 microdeletions. Eur J Med Genet 53: 213-216 (2010).

Zou D, McSweeney C, Sebastian A, Reynolds DJ, Dong F, et al: A critical role of RBM8a in proliferation and differentiation of embryonic neural progenitors. Neural Dev 10:18 (2015). 